\title{
Effectiveness of Bioinoculants Bacillus cereus and Trichoderma asperellum as Oil Palm Seedlings Growth Promoters
}

\author{
Tuan Hassan Tuan Muhammad Syafiq ${ }^{1}$, Syd Ali Nusaibah ${ }^{1 *}$ and Mohd Yusop Rafii ${ }^{2}$ \\ ${ }^{1}$ Department of Plant Protection, Faculty of Agriculture, Universiti Putra Malaysia, \\ 43400, Serdang, Selangor, Malaysia \\ ${ }^{2}$ Institute of Tropical Agriculture and Food Security, Universiti Putra Malaysia, \\ 43400, Serdang, Selangor, Malaysia
}

\begin{abstract}
In the establishment of oil palm seedlings, apart from the application of adequate amount of fertilizers, other sustainable plant nutrient sources are known to have the potential in enhancing vegetative growth and improve plants' resistance against pests and diseases. The application of plant growth promoters is known to contribute towards sustaining healthy plant growth leading to strong plant defense mechanisms. The present study was conducted to determine plant growth promotion potentials of bacterium, Bacillus cereus (UPM15) and fungus Trichoderma asperellum (UPM16). Isolates B. cereus and T. asperellum were assessed on their effectiveness as plant growth promoters for oil palm seedlings. Plant growth-promoting potentials were evaluated in terms of their ability to produce indole acetic acid (IAA), a naturally occurring plant hormone of the auxin class, iron-chelating compounds or siderophores, and phosphate solubilisation, considered to be one of the most important traits associated with plant phosphate nutrition. A series of treatments was applied to establish the potential of B. cereus and T. asperellum as microbial inoculants in singles and mixed applications in an in vivo nursery study. The ability to solubilize precipitated phosphate and

ARTICLE INFO

Article history:

Received: 14 August 2020

Accepted: 04 January 2021

Published: 24 February 2021

DOI: https://doi.org/10.47836/pjtas.44.1.09

E-mail addresses:

syafiqhassan_93@yahoo.com

(Tuan Hassan Tuan Muhammad Syafiq)

nusaibah@upm.edu.my (Syd Ali Nusaibah)

mrafii@upm.edu.my (Mohd Yusop Rafii)

* Corresponding author

to produce siderophores was positively demonstrated by $T$. asperellum. Both $B$. cereus and $T$. asperellum were capable of producing IAA. The results showed that the former significantly contributed towards growth enhancement of roots and the later in growth promotion of aerial parts of oil palm seedlings. Mixture of these isolates
\end{abstract}


yielded good vegetative growth. The study revealed the benefits of microbial inoculants that extended beyond their capacity as biofertilizers.

Keywords: Bacillus cereus, IAA production, phosphate solubilisation, plant growth promoter, siderophore, Trichoderma asperellum

\section{INTRODUCTION}

Synthetic or chemical fertilizers have been continuously used in agriculture for decades. Although effective in most cases, continuous and excessive use of synthetic fertilizers could cause negative impacts on the hydrological systems and soil environment (Salman et al., 2011; Wuana et al., 2011). The nutrients present in fertilizers can be mobilized by rainfall and eventually cause eutrophication (the nutrient enrichment of surface water bodies). Eutrophication enables aquatic plants and algal to grow uncontrollably and causes the reduction of dissolved oxygen which leads to adverse effects on aquatic life (M. N. Khan et al., 2018). Nitrogen-based fertilizers can cause nitrate contamination in the hydrological system, and in the worst case scenario, the consumption of nitrate-contaminated water can cause blue baby syndrome in infants and stomach cancer in adults (Nolan et al., 2002; Wolfe \& Patz, 2002). According to S. Khan et al. (2008), land application of fertilizers may cause soil contamination due to the accumulation of heavy metals and metalloids in the soil. Heavy metals can remain in the soil for a longer period after their introduction and their presence can severely inhibit the biodegradation of organic contaminants (Adriano, 2003; Maslin \& Maier, 2000). The situation remains a concern and thus, it has become crucial to explore alternative methods of crop fertilization with the objective of minimizing or even preventing chemical fertilizer application. Therefore, studies beneficial microbes or plant growth promoters, as alternative fertilizers, being regarded as a sustainable approach, are on the increase. Bacteria of the genus Bacillus spp. and Trichoderma spp. in the fungi family have been reported to have significantly enhanced plant growth and development of a number of species, boosting their defense mechanism towards biotic and abiotic stresses (Harman et al., 2004; Musa et al., 2018; Shoresh et al., 2005; Vinale et al., 2008; Yedidia et al., 2003). L. Zhao et al. (2011) and Naher et al. (2012) proposed that Bacillus spp. and Trichoderma spp. species could be potential plant growth promoters in agriculture. Against this background, the present study was conducted to examine the effectiveness of bioinoculants Bacillus cereus (UPM 15) and Trichoderma asperellum (UPM 16) as plant growth promoters on oil palm seedlings' growth and development.

\section{MATERIALS AND METHODS}

\section{Plant Materials and Soil Preparation}

A total of 96 oil palm seedlings of variant GH500 (Dura $\times$ Pisifera) were purchased from a commercial nursery. The 3-month old seedlings were certified as basal stem rot disease-free. The seedlings were maintained following standard nursery 
practices in a plant nursery facility at Faculty of Agriculture, Universiti Putra Malaysia, Serdang, Selangor. Standand NPK (15:15:15) fertilizer was applied to all treatments once a fortnight throughout the trial duration. The seedlings were irrigated twice daily at $11.00 \mathrm{a} . \mathrm{m}$. and after $4.00 \mathrm{p}$. $\mathrm{m}$. Plant trays containing the 3-month old seedlings were kept on hold at the nursery facility for two weeks before transferring them to polybags to stabilize and adapt to the new nursery environment. Polythene bags of $30 \mathrm{~cm} \times 38 \mathrm{~cm}$ with a thickness of 500 gauges $(0.125 \mathrm{~mm})$ were each used to hold $3 \mathrm{~kg}$ of soil mixture. Prior to transplanting, a soil mixture of $3: 2: 1 \mathrm{v} / \mathrm{v} / \mathrm{v}$ topsoil: peat: sand was prepared and sterilized in an autoclave at $121^{\circ} \mathrm{C}$ with $100 \mathrm{kPa}$ pressure for 30 minutes at Microbe Control Laboratory, Faculty of Agriculture, UPM.

\section{Treatments on Oil Palm Seedlings}

In the present study, bacterium $B$. cereus and fungi $T$. asperellum previously isolated from oil palm roots in two different studies focusing on biological control of oil palm basal stem rot disease by Musa et al. (2018) and Nusaibah et al. (2017) respectively, were used. Isolates of $B$. cereus, cultured on nutrient agar (NA) for 48 hours, were used to prepare inoculum suspension. A CFU $\mathrm{mL}^{-1}$ of $10^{8}$ was used to fix the inoculum suspension (Zaiton et al., 2008). An amount of $150 \mathrm{~mL}$ of $B$. cereus inoculum suspension was used to drench the seedling soil as shown in Table 1. A booster application of B. cereus was applied with similar protocol after 21 days from the initial application. Booster application was chosen to be applied at day 21 after testing a few time frames in a preliminary study based on the recovery data of each microbe used in the current study.

Preparation of conidial suspension of T. asperellum was carried out based on Izzati and Abdullah (2008) with some modifications. Muslin cloth was used to replace the filter paper Grade $1(11 \mu \mathrm{m})$. Seven-day old conidia from $T$. asperellum culture grown on potato dextrose agar (PDA) were harvested. The conidia were dislodged using an L-shaped glass rod with $10 \mathrm{~mL}$ of sterile distilled water. The conidia suspension was then filtered through Whatman ${ }^{\circledR}$ Grade 1 filter paper. Subsequently, the filtered suspension was made up to $1 \mathrm{~L}$ with sterile distilled water. Conidia counts were fixed in the range of $10^{8}$ conidia $/ \mathrm{mL}$. Precisely, $250 \mathrm{~mL}$ of the filtered suspension was used to drench the soil around the stem of each seedling as

Table 1

Treatments for in vivo nursery trial to assess oil palm seedling growth promotion

\begin{tabular}{ll}
\hline Treatment & Description \\
\hline BT & Plant + Trichoderma asperellum + Bacillus cereus \\
T & Plant + Trichoderma asperellum \\
B & Plant + Bacillus cereus \\
UC & + Plant (Untreated negative control) \\
\hline
\end{tabular}


set in Table 1. A booster application with similar concentration was applied 21 days after initial application.

\section{Vegetative Growth Assessment of Oil Palm Seedlings}

In determining the effects of treatments on oil palm seedling growth and development, parameters such as plant height, root dry weight, top dry weight (stem to leaf), bole girth size, bole weight, and chlorophyll content were recorded throughout the nursery trial on a monthly basis followed by destructive sampling at the end of the treatments after a duration of 6 months. A measuring tape was used to measure plant height from soil level to the most elevated seedling leaf. Harvested seedling parts, such as dry top and root weights, were measured and recorded using analytical balance (A\&D Company, GF-300) after a drying process in an oven at $70^{\circ} \mathrm{C}$ for 72 hours. Chlorophyll content or "greenness" was measured by Spectrum SPAD 502 Plus meter.

\section{Experimental Design and Statistical Analysis}

A randomised complete block design (RCBD) of 4 treatments with 12 oil palm seedlings for each treatment was used as the experimental design for the in vivo nursery trial. The 48 oil palm seedlings in the polythene bags were arranged on 6 benches in a randomized manner. Therefore, each bench would be a block, and all treatments were randomly assigned to every block. Block factors, namely different light, temperature, and moisture conditions that could affect the response variable were also taken into consideration. The selection of RCBD design in this study was able to eliminate the bias factors particularly the light factor. Light is a vital factor of plant growth via photosynthesis. Therefore, the current study managed to be assessed solely on the effects by plant growth promoters applied. All data were subjected to analysis of variance (ANOVA) with means comparison by least significant difference (LSD) at $p \leq 0.05$ using SAS ${ }^{\circledR}$ software version 9.4 (SAS Institute Inc., 1995).

\section{Production of Indole Acetic Acid (IAA)}

Indole acetic acid (IAA), synthesized by $B$. cereus and T. asperellum isolates, was measured calorimetrically using Salkowski's reagent following procedures of Glickmann and Dessaux (1995) as well as Gordon and Weber (1951) respectively. The method quantified the amount of IAA produced in aqueous solution containing precursor L-tryptophan. A standard curve using a series of IAA dilutions were generated at $0,50,100,150,200,250,300,350$, and $400 \mu \mathrm{g} / \mathrm{mL}$ to quantify the amount of IAA produced by both $B$. cereus and $T$. asperellum.

Bacillus cereus isolate was cultured in a nutrient broth (NB) (Difco ${ }^{\mathrm{TM}}$ ) at $28 \pm 2{ }^{\circ} \mathrm{C}$ on a shaker at $150 \mathrm{rpm}$. After 24 hours, 1 $\mathrm{mL}$ of bacterial culture from previous $\mathrm{NB}$ was pipetted into $100 \mathrm{~mL}$ of modified NB (Difco ${ }^{\mathrm{TM}}$ ) (added with $5 \mathrm{~mL}$ of $100 \mathrm{mg} \mathrm{L}^{-1}$ of L-tryptophan solution). The bacterium was allowed to grow in the modified NB 
(Difco ${ }^{\mathrm{TM}}$ ) for 48 hours. An amount $1.5 \mathrm{~mL}$ of bacterial culture was centrifuged for 5 minutes at 1, $7709 \mathrm{xg}$. Upon completion of centrifugation, $1 \mathrm{~mL}$ of supernatant was pipetted out and added to $2 \mathrm{~mL}$ of Salkowski's reagent. A spectrophotometer (Thermo Fisher Scientific, Finland) was used to record colour densities of the mixture at $530 \mathrm{~nm}$ after incubating for 25 minutes at room temperature.

For culture of T. asperellum, $200 \mathrm{~mL}$ of potato dextrose broth (PDB) (Difco ${ }^{\mathrm{TM}}$ ), modified by adding $5 \mathrm{~mL}$ of $100 \mathrm{mg} \mathrm{L}^{-1}$ L-tryptophan solution was used. Conidial suspension at $10^{8}$ of $T$. asperellum was used to inoculate the modified (added with L-tryptophan solution) PDB (Difco ${ }^{\mathrm{TM}}$ ) and incubated for 8 days at room temperature. Subsequently, conidial suspension was centrifuged for ten minutes at $1,107 \mathrm{xg}$ and filtered through a $0.22 \mu \mathrm{m}$ syringe filter. An amount $1 \mathrm{~mL}$ of supernatant was pipetted out and mixed with 2 drops of orthophosphoric acid (Sigma-Aldrich, USA) and $2 \mathrm{ml}$. of Salkowski's reagent $\left(2 \%\right.$ of $0.5 \mathrm{M} \mathrm{FeCl}_{3}$ in $35 \% \mathrm{HClO}_{4}$ solution). Thermo Scientific Multiskan GO spectrophotometer (Thermo Fisher Scientific, Finland) was used to record colour densities of the mixture after incubating for 20 minutes in the dark at room temperature. The spectrometer was set at $530 \mathrm{~nm}$ absorbance.

\section{Siderophore Production Assay}

Siderophore production assay was carried out following procedure used by Alexander and Zuberer (1991). Four solutions were prepared, sterilized separately and mixed to produce chrome azurol sulphonate (CAS) agar based on their formula. Chrome azurol sulphonate (CAS) agar was poured into Petri plates and allowed to solidify. A cork-borer ( $5 \mathrm{~mm}$ in size) was used to punch four holes on each of the 14 CAS agar plate. Bacterial inocula and conidia suspension each at $100 \mu \mathrm{L}$ were dispensed into the holes of the agar in separate plates. The Petri plates were incubated for 7 days at $28 \pm 2^{\circ} \mathrm{C}$. The capability to yield siderophore was determined by measuring the diameter of orange halos exhibited after the duration of incubation.

\section{Phosphate Solubilization Test}

Phosphate solubilization test was done following the procedure of Mehta and Nautiyal (2001). Both UPM 15 and UPM 16 isolates were inoculated into NB (Difco ${ }^{\mathrm{TM}}$ ) and PDB (Difco ${ }^{\mathrm{TM}}$ ) respectively. A corkborer ( $5 \mathrm{~mm}$ in size) was used to punch four holes on each of the National Botanical Research Institute (NBRIP) agar plate (14 replicates were prepared for each treatment). After 48 hours of inoculation, $100 \mu \mathrm{L}$ of bacterial inoculum and conidial suspension were dispensed into the holes of the agar medium. The Petri plates were incubated for 7 days at $28 \pm 2{ }^{\circ} \mathrm{C}$. The presence of clear zones around the bacterial and fungal colonies was used as indicators for positive phosphate solubilization. The effectiveness of the microbes to solubilize phosphate was determined by measuring the diameter of the clear zones. 


\section{RESULTS}

\section{Influence of Plant Growth Promoters on Vegetative Growth Oil Palm Seedlings}

Single applications of $T$. asperellum treatments recorded the highest plant height $(86.9 \mathrm{~cm})$, followed by the single applications of $B$. cereus with $85.3 \mathrm{~cm}$ (Table 2). Nevertheless, the plant height for all treatments significantly increased between the start of treatments and 6 months after. Figure 1 shows visible differences on oil palm seedling height for all treatments.

Table 2

Impact of application of plant growth promoters on oil palm seedling vegetative parameters

\begin{tabular}{|c|c|c|c|c|c|}
\hline \multirow[b]{2}{*}{ Treatments } & \multicolumn{5}{|c|}{ Vegetative parameters (average readings) } \\
\hline & Height (cm) & Bole size $(\mathrm{cm})$ & $\begin{array}{l}\text { Bole dry weight } \\
\text { (g) }\end{array}$ & $\begin{array}{c}\text { Top dry weight } \\
\text { (g) }\end{array}$ & $\begin{array}{l}\text { Root dry weight } \\
\text { (g) }\end{array}$ \\
\hline BT & $81.0 \pm 2.3^{b}$ & $3.80 \pm 0.08^{\mathrm{a}}$ & $36.0 \pm 2.5^{\mathrm{a}}$ & $215.0 \pm 36.7^{\mathrm{a}}$ & $80.0 \pm 10.9^{\mathrm{a}}$ \\
\hline $\mathrm{T}$ & $86.9 \pm 3.1^{\mathrm{a}}$ & $3.40 \pm 0.05^{\mathrm{b}}$ & $31.4 \pm 2.1^{\mathrm{a}}$ & $219.8 \pm 24.0^{\mathrm{a}}$ & $63.8 \pm 6.8^{\mathrm{ab}}$ \\
\hline B & $85.3 \pm 2.7^{\mathrm{a}}$ & $3.40 \pm 0.08^{\mathrm{b}}$ & $32.3 \pm 1.2^{\mathrm{a}}$ & $161.3 \pm 10.8^{\mathrm{ab}}$ & $71.3 \pm 13.8^{\mathrm{ab}}$ \\
\hline $\mathrm{UC}$ & $77.1 \pm 2.2^{\mathrm{c}}$ & $3.10 \pm 0.05^{\mathrm{c}}$ & $31.1 \pm 0.9^{\mathrm{a}}$ & $117.5 \pm 5.6^{\mathrm{b}}$ & $45.0 \pm 9.1^{\mathrm{c}}$ \\
\hline
\end{tabular}

Note. Values are the means \pm S.E. $(\mathrm{n}=12)$. Means followed by same letters in the same columns and rows are not significantly different at $p=0.05$ using Duncan's multiple range test. Treatments: BT = Bacillus cereus + Trichoderma asperellum, $\mathrm{T}=$ Trichoderma asperellum, $\mathrm{B}=$ Bacillus cereus, $\mathrm{UC}=$ Untreated control

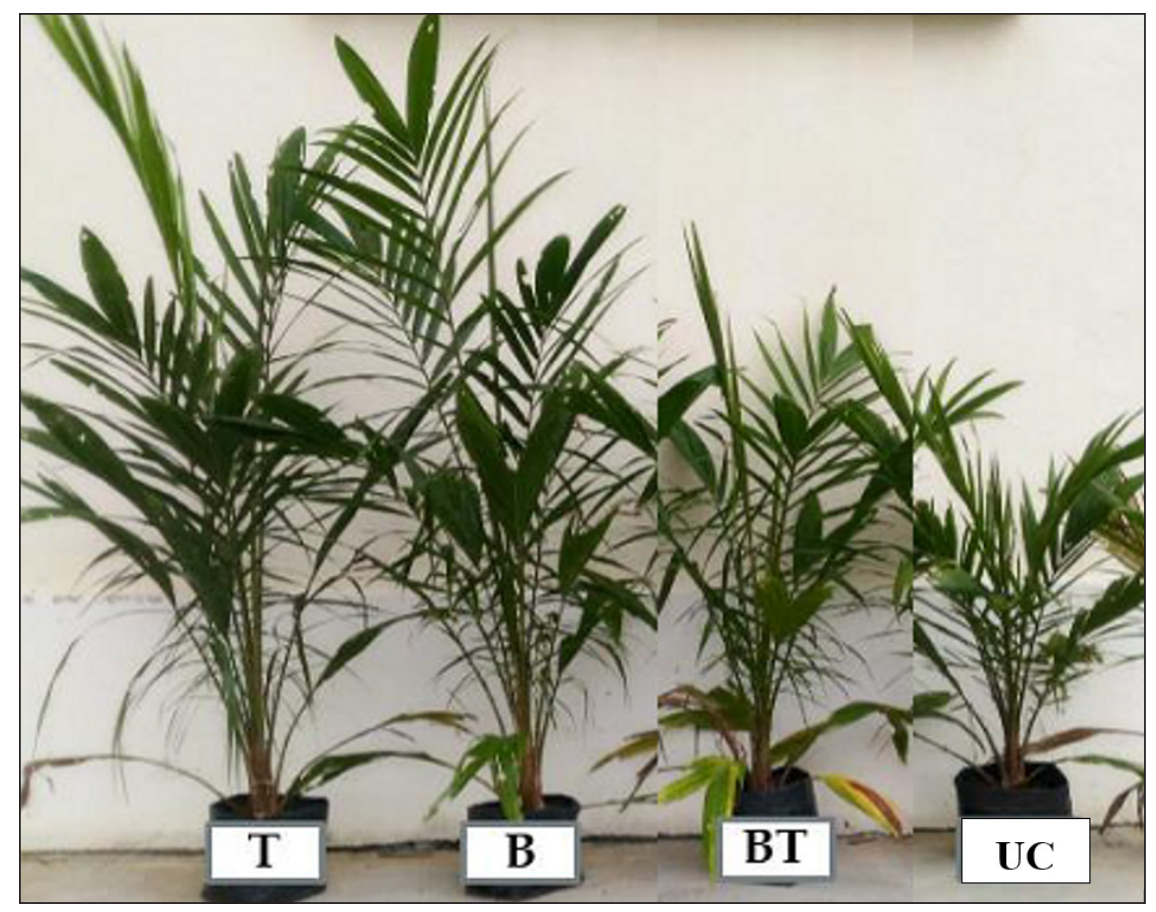

Figure 1. Visible view of oil palm seedling height for all the treatments at 6 months after treatment. Scale bar represents $10 \mathrm{~cm}$ (Note. Treatments: $\mathrm{BT}=$ Bacillus cereus + Trichoderma asperellum, $\mathrm{T}=$ Trichoderma asperellum, $\mathrm{B}=$ Bacillus cereus, $\mathrm{UC}=$ Untreated control) 
The present study recorded that bole size in almost all treatments showed no significant difference except for $B$. cereus and untreated control treatments (UC). Mixed application of $B$. cereus contributed the highest bole girth size of $3.80 \mathrm{~cm}$. Mixed application also recorded the weightiest dry bole weight of $36.0 \mathrm{~g}$ (Table 2).

Data on top weight implied that $T$. asperellum enhanced the growth of top parts of the seedlings. Single applications of $T$. asperellum and mixed applications of $B$. cereus and T. asperellum were significantly superior to other treatments, recording 219.8 $\mathrm{g}$ and $215.0 \mathrm{~g}$ of dry top weight respectively (Table 2). Mixed applications of B. cereus and $T$. asperellum were able to produce the

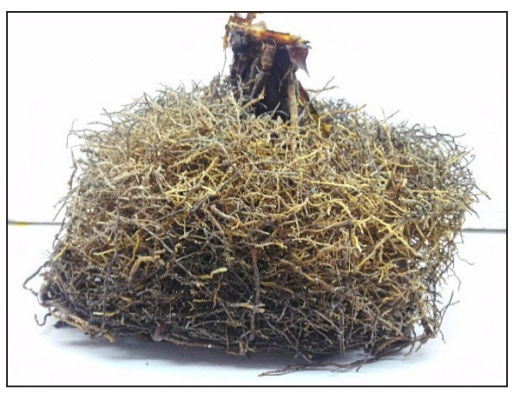

(a)

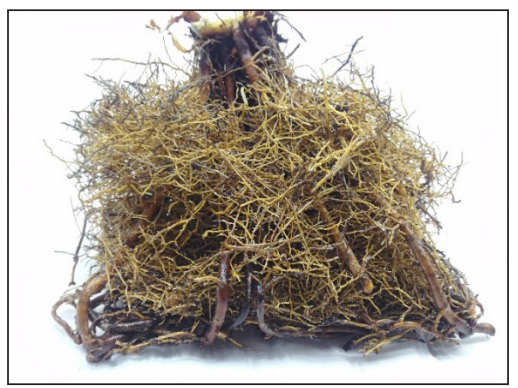

(c) heaviest root dry weight $(80.0 \mathrm{~g})$, and single applications of $B$. cereus yielded $71.3 \mathrm{~g}$ of dry weight (Table 2). Figure 2 shows the visible abundance of oil palm roots in the treatments.

Data on the chlorophyll content demonstrated that chlorophyll content started to decrease at 2 months. A slight increase was noted at 6 months. At 6 months, treatment with $T$. asperellum gave the highest chlorophyll content with $41.9^{a}$ SPAD unit, followed by untreated control (40.9 a SPAD unit), treatment B. cereus (41.1 ${ }^{\text {a }}$ SPAD unit), and mixture treatment

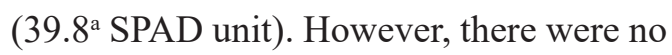
significant differences in chlorophyll content between all treatments (Table 3).

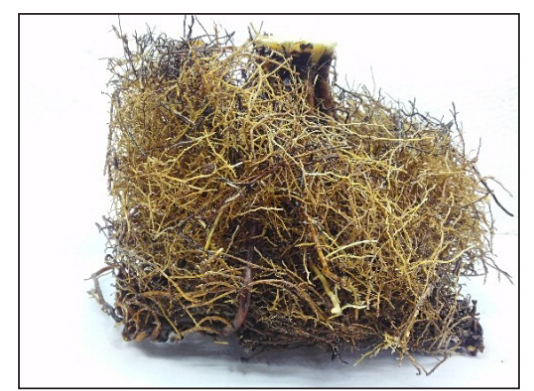

(b)

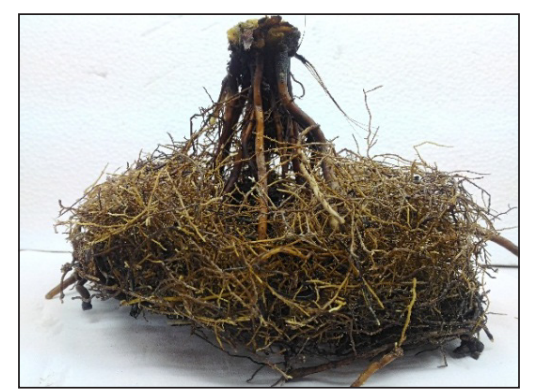

(d)

Figure 2. Visibility of oil palm seedling roots for all the treatments at 6 months after treatment: (a) BT = Bacillus cereus + Trichoderma asperellum; (b) $\mathrm{T}=$ Trichoderma asperellum; (c) B = Bacillus cereus; and (d) $\mathrm{UC}=$ Untreated control 
Table 3

Effect of Trichoderma asperellum and Bacillus cereus on chlorophyll content of oil palm

\begin{tabular}{lccccccc}
\hline \multirow{2}{*}{ Treatments } & \multicolumn{7}{c}{ Month after inoculation (MAI) (SPAD unit) } \\
\cline { 2 - 8 } & MAI 0 & MAI 1 & MAI 2 & MAI 3 & MAI 4 & MAI 5 & MAI 6 \\
\hline BT & $50.0 \pm 1.7^{\mathrm{ab}}$ & $52.4 \pm 1.5^{\mathrm{a}}$ & $47.5 \pm 1.4^{\mathrm{a}}$ & $40.4 \pm 1.4^{\mathrm{a}}$ & $37.5 \pm 1.7^{\mathrm{a}}$ & $35.3 \pm 1.3^{\mathrm{a}}$ & $39.8 \pm 2.3^{\mathrm{a}}$ \\
T & $50.7 \pm 1.7^{\mathrm{ab}}$ & $51.6 \pm 1.9^{\mathrm{a}}$ & $38.7 \pm 1.6^{\mathrm{b}}$ & $38.2 \pm 1.7^{\mathrm{a}}$ & $37.4 \pm 1.5^{\mathrm{a}}$ & $35.6 \pm 2.3^{\mathrm{a}}$ & $41.9 \pm 2.6^{\mathrm{a}}$ \\
$\mathrm{B}$ & $53.3 \pm 1.8^{\mathrm{a}}$ & $52.3 \pm 1.6^{\mathrm{a}}$ & $45.4 \pm 1.8^{\mathrm{a}}$ & $43.1 \pm 1.8^{\mathrm{a}}$ & $41.2 \pm 1.7^{\mathrm{a}}$ & $38.8 \pm 2.6^{\mathrm{a}}$ & $41.1 \pm 1.8^{\mathrm{a}}$ \\
UC & $47.3 \pm 1.8^{\mathrm{b}}$ & $50.7 \pm 2.6^{\mathrm{a}}$ & $45.1 \pm 1.4^{\mathrm{a}}$ & $42.4 \pm 1.7^{\mathrm{a}}$ & $36.3 \pm 2.2^{\mathrm{a}}$ & $40.1 \pm 1.8^{\mathrm{a}}$ & $40.9 \pm 1.5^{\mathrm{a}}$ \\
\hline
\end{tabular}

Note. Values are the means \pm S.E. $(\mathrm{n}=12)$. Means followed by same letters in the same columns and rows are not significantly different at $p=0.05$ using Duncan's multiple range test. Treatments: $\mathrm{BT}=$ Bacillus cereus + Trichoderma asperellum, $\mathrm{T}=$ Trichoderma asperellum, $\mathrm{B}=$ Bacillus cereus, $\mathrm{UC}=$ Untreated control

Table 4

Plant growth promotion traits exhibited by bioinoculants on oil palm seedlings

\begin{tabular}{|c|c|c|c|}
\hline \multirow{2}{*}{ Bioinoculant } & IAA production & Siderophore production assay & Phosphate solubilization test \\
\hline & $\begin{array}{c}\text { [Mean IAA production } \\
(\mathrm{ug} / \mathrm{ml})]\end{array}$ & [Mean orange halos $(\mathrm{cm})]$ & $\begin{array}{c}\text { [Mean clear zone } \\
(\mathrm{cm})]\end{array}$ \\
\hline Bacillus cereus & $9.99 \pm 0.03^{\mathrm{a}}$ & $0.40 \pm 0.01^{\mathrm{b}}$ & $0.60 \pm 0.01^{\mathrm{b}}$ \\
\hline $\begin{array}{l}\text { Trichoderma } \\
\text { asperellum }\end{array}$ & $5.83 \pm 0.02^{b}$ & $2.90 \pm 0.04^{\mathrm{a}}$ & $1.00 \pm 0.03^{\mathrm{a}}$ \\
\hline
\end{tabular}

Note. Values are the means \pm S.E. $(n=12)$. Means followed by same letters in the same columns and rows are not significantly different at $p=0.05$ using Duncan's multiple range test

\section{Indole Acetic Acid (IAA) Production}

In the present study, the treatment with $B$. cereus $\left(9.99 \pm 0.03^{\mathrm{a}} \mu \mathrm{g} / \mathrm{mL}\right)$ produced more IAA than with $T$. asperellum $\left(5.83 \pm 0.02^{\mathrm{b}}\right.$ $\mu \mathrm{g} / \mathrm{mL}$ ) as shown in Table 4 . However, both isolates were able to produce IAA which was one of the most vital aspects in selecting plant growth promoters in terms of plant growth promotion traits.

\section{Siderophore Production Ability}

The presence of orange halos indicated the production of siderophore by the isolates. After 7 days of incubation in the culture chamber, T. asperellum showed significantly larger measurement of orange halos at 2.9 $\pm 0.04 \mathrm{~cm}$ compared to $B$. cereus which exhibited only $0.4 \pm 0.01 \mathrm{~cm}$ (Table 4$)$. Both microbes confirmed the ability to produce siderophore.

\section{Phosphate Solubilization Test}

Both isolates in the present study were found to be able to solubilize phosphate when tested using NBRIP medium. After 7 days of incubation at room temperature, $T$. asperellum gave significantly higher average clear zones which were $1.0 \mathrm{~cm}$ compared to $B$. cereus that gave only an average of $0.6 \mathrm{~cm}$ clear zone (Table 4$)$. In the test, the bigger the average measurement of clear zones, the greater the ability of the microbes to solubilize phosphate. 


\section{DISCUSSION}

Awareness on the importance of sustainable practices in the application of fertilizers in the plantation sector occurred quite recently. In the past, agricultural producers had been relying on chemical fertilizers to be applied in the plantations. Planters had little or no awareness of the longterm harmful effects of chemical fertilizer application. They routinely used chemical fertilizers due to being readily available, easy to use and typically result is instant (Cawoy et al., 2011; Ntow et al., 2006). However, awareness on the possible harmful effects to the planters themselves and the environment at large has encouraged use of bioinoculants as an alternative to chemical fertilizers, approaching towards minimal use of chemicals (Cawoy et al., 2011). According to Chen et al. (2012), microbes that live in the soil have the potential to be used as plant growth promoters as the soil rhizospheres act as the first line of defense for plant's roots against pathogens. Bacillus cereus and T. asperellum isolates used in the present study were previously isolated from oil palm roots in two different studies by Musa et al. (2018) and Nusaibah et al. (2017), respectively. The two isolates were proven to be excellent Ganoderma boninense growth suppressors via in vitro and in vivo tests and trials (Musa et al., 2018; Nusaibah et al., 2017).

In the present study, enhanced vegetative growth was demonstrated in treated seedlings when compared to untreated seedlings. Mixed treatments of T. asperellum and B. cereus demonstrated a significant increase in bole, top and root weights. These discoveries were in agreement with Nusaibah et al. (2017). Another significant finding was on the application of T. asperellum which yielded superior plant height compared to other treatments. The findings were in consistence with Harman et al. (2004) who reported that Trichoderma sp. improved nutrient uptake in maize and subsequently enhanced plant growth.

Inoculant of $B$. cereus performed better in increasing the bole and root weights of the seedlings. A previous study by J. L. Zhao et al. (2010) demonstrated that bacterial polysaccharide extracted from $B$. cereus significantly improved the biomass of Salvia miltiorrhiza hairy roots. Dawwam et al. (2013) reported that the application of $B$. cereus as a biofertilizer constituent showed positive plant growth promoting trait.

The present study revealed that the application of both microbes did not have any significant impact on chlorophyll content. These findings were consistent with Pereira et al. (2015), who reported that Azospirillum brasilense did not significantly influence chlorophyll content of maize. The present findings did not complement a research conducted by Anuar et al. (2015), where fungus Phlebia sp. isolate increased all vegetative growth parameters of oil palm including total chlorophyll content.

Production of IAA, phosphate solubilisation ability, and siderophore production were parameters assessed for plant growth promotion activities of the microbes under study. Work by Simon et al. (2013) showed that both B. cereus and 
T. asperellum demonstrated the ability to produce IAA, the most active auxin. The present findings were also consistent with other studies which demonstrated the ability of Bacillus spp. and T. asperellum to produce IAA that, in turn, promoted plant growth and played roles in plants defense responses (Hermosa et al., 2012; Husen, 2003).

Phosphorus is one of the most inadequate elements present in soil compared to other macronutrients (Bünemann et al., 2010). However, there are some microbes that have the ability to solubilize precipitated phosphate into a suitable form for plant uptake (Kang et al., 2002; Pradhan \& Sukla, 2006). Thus, in selecting excellent plant growth promoters, the ability of microbes to solubilize phosphate should be considered. The present study conducted using NBRIP gar medium, demonstrated that B. cereus and T. asperellum had the ability to solubilize phosphate. These findings were in agreement with L. Zhao and Zhang (2015) which disclosed that T. asperellum could solubilize inorganic and organic phosphates. Maheswar and Sathiyavani (2012) reported that Bacillus cereus and Bacillus subtilis were active in solubilization of tricalcium phosphate under in vitro conditions. Jones and Oburger (2011) also stated that several species of soil bacteria such as Pseudomonas, Azotobacter, Burkholderia, Bacillus, and Rhizobium were able to solubilize precipitated phosphates.

Various bacteria, fungi, plants, and yeast have been reported to produce and release siderophore to up take ferric ion from the environment (Chu et al., 2010).
Iron is required in vital processes such as chlorophyll production (Encarnação et al., 2012) and enzyme functions (Ghasemian \& Ghalavand, 2010; Grotz \& Guerinot, 2006) in maintaining plant health. Therefore, one the most essential traits of potential plant growth promoters is the ability to produce siderophore. The results of the present study indicated that both $B$. cereus and $T$. asperellum exhibited positive siderophore production. The findings were consistent with Qi and Zhao (2013) that showed T. asperellum with capabilities of producing siderophores of up to $96.6 \%$ siderophore units after 2 days on CAS agar medium. Triveni et al. (2013) also demonstrated that Trichoderma-Bacillus and TrichodermaPseudomonas biofilms exhibited higher siderophore production.

The in vitro assessment conducted on isolates $B$. cereus and $T$. asperellum demonstrated their ability in contributing towards plant growth promotion traits in a controlled environment. However, the in vitro studies supported the physiological parameters assesed via in vivo study. For instance, highest concentration of IAA was produced by $B$. cereus in vitro which correlates with the highest root dry weight in $B$. cereus treated oil palm seedlings. IAA is the most abundant and basic auxin hormone produced in the roots, stem and bud. Nonetheless, the highest top dry weight could be interrelated with the efficientcy of $T$. asperellum in producing siderophore and solubilizing phosphate, which is involved in the synthesis of chorophyll and adenosine 5'-triphosphate 
(ATP), respectively. Phosphorus is a dynamic component structure of ATP used for performing photosynthesis. Results provided further support that these 2 isolates could be considered as potential plant growth promoters and could be tested via nursery trial (in vivo) to evaluate their effectiveness against basal stem rot disease of oil palm.

\section{CONCLUSION}

The present study concluded that Trichoderma asperellum contributed significantly towards growth of aerial parts while Bacillus cereus towards root growth of oil palm seedlings. Mixed treatments of T. asperellum and B. cereus complemented each other in contributing towards a wholesome plant growth promotion effects on the oil palm seedlings. As bioinoculants, the study proved that the in vitro assessment conducted on B. cereus and T. asperellum isolates demonstrated their abilities in producing compounds that might have contributed towards significant plant growth promotion activities of oil palm seedlings.

\section{ACKNOWLEDGMENT}

Putra Grant-IPS via Research and Management Centre (RMC), Universiti Putra Malaysia (UPM) (Grant No: GPIPS/2016/9503700).

\section{REFERENCES}

Adriano, D. C. (2003). Trace elements in terrestrial environments: Biogeochemistry bioavailability and risks of metals ( $2^{\text {nd }}$ ed.). Springer. https:// doi.org/10.1007/978-0-387-21510-5
Alexander, D. B., \& Zuberer, D. A. (1991). Use of chrome azurol $\mathrm{S}$ reagents to evaluate siderophore production by rhizosphere bacteria. Biology and Fertility of Soils, 12(1), 39-45. https://doi. org/10.1007/BF00369386

Anuar, E. N., Nulit, R., \& Idris, A. S. (2015). Growth promoting effects of endophytic fungus Phlebia GanoEF3 on oil palm (Elaeis guineensis) seedlings. International Journal of Agriculture and Biology, 17(1), 135-141.

Bünemann, E. K., Oberson, A., \& Frossard, E. (Eds.). (2010). Phosphorus in action: Biological processes in soil phosphorus cycling. Springer. https://doi.org/10.1007/978-3-642-15271-9

Cawoy, H., Bettiol, W., Fickers, P., \& Ongena, M. (2011). Bacillus-based biological control of plant diseases. https://www.intechopen.com/books/ pesticides-in-the-modern-world-pesticides-useand-management/bacillus-based-biologicalcontrol-of-plant-diseases

Chen, Z. H., Chen, L. J., \& Wu, Z. J. (2012). Relationships among persistence of Bacillus thuringiensis and Cowpea trypsin inhibitor proteins, microbial properties and enzymatic activities in rhizosphere soil after repeated cultivation with transgenic cotton. Applied Soil Ecology, 53, 23-30. https://doi.org/10.1016/j. apsoil.2011.10.019

Chu, B. C., Garcia-Herrero, A., Johanson, T. H., Krewulak, K. D., Lau, C. K., Peacock, R. S., Slavinskaya, Z., \& Vogel, H. J. (2010). Siderophore uptake in bacteria and the battle for iron with the host; a bird's eye view. Biometals, 23(4), 601-611. https://doi.org/10.1007/s10534010-9361-x

Dawwam, G. E., Elbeltagy, A., Emara, H. M., Abbas, I. H., \& Hassan, M. M. (2013). Beneficial effect of plant growth promoting bacteria isolated from the roots of potato plant. Annals of Agricultural Sciences, 58(2), 195-201. https:// doi.org/10.1016/j.aoas.2013.07.007 
Encarnação, T., Burrows, H. D., Pais, A. C., Campos, M. G., \& Kremer, A. (2012). Effect of $\mathrm{N}$ and $\mathrm{P}$ on the uptake of magnesium and iron and on the production of carotenoids and chlorophyll by the microalgae Nannochloropsis sp.. Journal of Agricultural Science and Technology, 2, 824-832.

Ghasemian, V., \& Ghalavand, A. (2010). The effect of iron, zinc and manganese on quality and quantity of soybean seed. Journal of Phytology, 2(11), 73-79.

Glickmann, E., \& Dessaux, Y. (1995). A critical examination of the specificity of the Salkowski reagent for indolic compounds produced by phytopathogenic bacteria. Applied Environmental Microbiology, 61(2), 793-796. https://doi. org/10.1128/AEM.61.2.793-796.1995

Gordon, S. A., \& Weber, R. P. (1951). Colorimetric estimation of indoleacetic acid. Plant Physiology, 26(1), 192-195. https://doi.org/10.1104/ pp.26.1.192

Grotz, N., \& Guerinot, M. L. (2006). Molecular aspects of $\mathrm{Cu}, \mathrm{Fe}$ and $\mathrm{Zn}$ homeostasis in plants. Biochimica et Biophysica Acta (BBA)-Molecular Cell Research, 1763(7), 595-608. https://doi. org/10.1016/j.bbamcr.2006.05.014

Harman, G. E., Howell, C. R., Viterbo, A., Chet, I., \& Lorito, M. (2004). Trichoderma speciesopportunistic, avirulent plant symbionts. Nature Reviews Microbiology, 2(1), 43-56. https://doi. org/10.1038/nrmicro797

Hermosa, R., Viterbo, A., Chet, I., \& Monte, E. (2012). Plant-beneficial effects of Trichoderma and of its genes. Microbiology, 158(1), 17-25. https://doi. org/10.1099/mic.0.052274-0

Husen, E. (2003). Screening of soil bacteria for plant growth activities in vitro. Indonesia Journal of Agriculture Science, 4(1), 27-31. https://doi. org/10.21082/ijas.v4n1.2003.p27-31
Izzati, M. Z. N. A., \& Abdullah, F. (2008). Disease suppression in Ganoderma-infected oil palm seedlings treated with Trichoderma harzianum. Plant Protection Science, 44(3), 101-107. https:// doi.org/10.17221/23/2008-PPS

Jones, D. L., \& Oburger, E. (2011). Solubilization of phosphorus by soil microorganisms. In E. K. Bünemann, A. Oberson, \& E. Frossard (Eds.), Phosphorus in action (pp. 169-198). Springer. https://doi.org/10.1007/978-3-642-15271-9_7

Kang, S. C., Ha, C. G., Lee, T. G., \& Maheshwari, D. K. (2002). Solubilization of insoluble inorganic phosphates by a soil-inhabiting fungus Fomitopsis sp. PS102. Current Science, 82(4), 439-442.

Khan, M. N., Mobin, M., Abbas, Z. K., \& Alamri, S. A. (2018). Fertilizers and their contaminants in soils, surface and groundwater. Encyclopedia of the Anthropocene, 5, 225-240. https://doi. org/10.1016/B978-0-12-809665-9.09888-8

Khan, S., Cao, Q., Zheng, Y. M., Huang, Y. Z., \& Zhu, Y. G. (2008). Health risks of heavy metals in contaminated soils and food crops irrigated with wastewater in Beijing, China. Environmental Pollution, 152(3), 686-692. https://doi. org/10.1016/j.envpol.2007.06.056

Maheswar, N. U., \& Sathiyavani, G. (2012). Solubilization of phosphate by Bacillus sp., from groundnut rhizosphere (Arachishypogaea L.). Journal of Chemical and Pharmaceutical Research, 4(8), 4007-4011.

Maslin, P., \& Maier, R. M. (2000). Rhamnolipidenhanced mineralization of phenanthrene in organic-metal co-contaminated soils. Bioremediation Journal, 4(4), 295-308. https://doi.org/10.1080/10889860091114266

Mehta, S., \& Nautiyal, C. S. (2001). An efficient method for qualitative screening of phosphatesolubilizing bacteria. Current Microbiology, 43(1), 51-56. https://doi.org/10.1007/ s002840010259 
Musa, H., Nusaibah, S. A., \& Khairulmazmi, A. (2018). Assessment on Trichoderma spp. mixture as a potential biocontrol agent of Ganoderma boninense infected oil palm seedlings. Journal of Oil Palm Research, 30(3), 403-415. https:// doi.org/10.21894/jopr.2018.0035

Naher, L., Yusuf, U. K., Siddiquee, S., Ferdous, J., \& Rahman, M.A. (2012). Effect of media on growth and antagonistic activity of selected Trichoderma strains against Ganoderma. African Journal of Microbiology Research, 6(48), 7449-7453. https://doi.org/10.5897/AJMR12.1216

Nolan, B. T., Hitt, K. J., \& Ruddy, B. C. (2002). Probability of nitrate contamination of recently recharged groundwaters in the conterminous United States. Environmental Science and Technology, 36(10), 2138-2145. https://doi. org/10.1021/es0113854

Ntow, W. J., Gijzen, H. J., Kelderman, P., \& Drechsel, P. (2006). Farmer perceptions and pesticide use practices in vegetable production in Ghana. Pest Management Science, 62(4), 356-365. https:// doi.org/10.1002/ps. 1178

Nusaibah, S. A., Saad, G., \& Tan, G. H. (2017). Antagonistic efficacy of Trichoderma harzianum and Bacillus cereus against Ganoderma disease of oil palm via dip, place and drench (DPD) artificial inoculation technique. International Journal of Agriculture and Biology, 19(2), 299306. https://doi.org/10.17957/IJAB/15.0280

Pereira, L. D. M., Pereira, E. D. M., Revolti, L. T. M., Zingaretti, S. M., \& Môro, G. V. (2015). Seed quality, chlorophyll content index and leaf nitrogen levels in maize inoculated with Azospirillum brasilense. Revista Ciência Agronômica, 46(3), 630-637. https://doi. org/10.5935/1806-6690.20150047

Pradhan, N., \& Sukla, L. B. (2006). Solubilization of inorganic phosphates by fungi isolated from agriculture soil. African Journal of Biotechnology, 5(10), 850-854.
Qi, W., \& Zhao, L. (2013). Study of the siderophoreproducing Trichoderma asperellum Q1 on cucumber growth promotion under salt stress. Journal of Basic Microbiology, 53(4), 355-364. https://doi.org/10.1002/jobm.201200031

Salman, J. M., Njoku, V. O., \& Hameed, B. H. (2011). Batch and fixed-bed adsorption of 2,4-dichlorophenoxyacetic acid onto oil palm frond activated carbon. Chemical Engineering Journal, 174(1), 33-40. https://doi.org/10.1016/j. cej.2011.08.024

Shoresh, M., Yedidia, I., \& Chet, I. (2005). Involvement of jasmonic acid/ethylene signaling pathway in the systemic resistance induced in cucumber by Trichoderma asperellum T203. Phytopathology, 95(1), 76-84. https://doi. org/10.1094/PHYTO-95-0076

Simon, S., Kubeš, M., Baster, P., Robert, S., Dobrev, P. I., Friml, J., Petrášek, J., \& Zažímalová, E. (2013). Defining the selectivity of processes along the auxin response chain: a study using auxin analogues. New Phytologist, 200(4), 10341048. https://doi.org/10.1111/nph.12437

Triveni, S., Prasanna, R., Shukla, L., \& Saxena, A. K. (2013). Evaluating the biochemical traits of novel Trichoderma-based biofilms for use as plant growth-promoting inoculants. Annals of Microbiology, 63(3), 1147-1156. https://doi. org/10.1007/s13213-012-0573-x

Vinale, F., Sivasithamparam, K., Ghisalberti, E. L., Marra, R., Barbetti, M. J., Li, H., Woo, S. L., \& Lorito, M. (2008). A novel role for Trichoderma secondary metabolites in the interactions with plants. Physiological and Molecular Plant Pathology, 72(1-3), 80-86. https://doi. org/10.1016/j.pmpp.2008.05.005

Wolfe, A. H., \& Patz, J. A. (2002). Reactive nitrogen and human health: Acute and long-term implications. AMBIO: A Journal of the Human Environment, 31(2), 120-125. https://doi. org/10.1579/0044-7447-31.2.120 
Wuana, R. A. \& Okieimen, F. E. (2011). Heavy metals in contaminated soils: A review of sources, chemistry, risks and best available strategies for remediation. International Scholarly Research Notices, 2011, 402647. https://doi. org/10.5402/2011/402647

Yedidia, I., Shoresh, M., Kerem, Z., Benhamou, N., Kapulnik, Y., \& Chet, I. (2003). Concomitant induction of systemic resistance to Pseudomonas syringae pv. lachrymans in cucumber by Trichoderma asperellum (T-203) and accumulation of phytoalexins. Applied Journal of Environmental Microbiology, 69(12), 73437353. https://doi.org/10.1128/aem.69.12.73437353.2003

Zaiton, S., Sariah, M., \& Ahmad, Z. A. M. (2008). Effect of endophytic bacteria on growth and suppression of Ganoderma infection in oil palm. International Journal of Agriculture Biology, 10(2), 127-132.
Zhao, J. L., Zhou, L. G., \& Wu, J. Y. (2010). Promotion of Salvia miltiorrhiza hairy root growth and tanshinone production by polysaccharideprotein fractions of plant growth-promoting rhizobacterium Bacillus cereus. Process Biochemistry, 45(9), 1517-1522. https://doi. org/10.1016/j.procbio.2010.05.034

Zhao, L., \& Zhang, Y. Q. (2015). Effects of phosphate solubilization and phytohormone production of Trichoderma asperellum Q1 on promoting cucumber growth under salt stress. Journal of Integrated Agriculture, 14(8), 1588-1597. https:// doi.org/10.1016/S2095-3119(14)60966-7

Zhao, L., Xu, Y., Sun, R., Deng, Z., Yang, W. \& Wei, G. (2011). Identification and characterization of the endophytic plant growth promoter Bacillus cereus strain MQ23 isolated from Sophora alopecuroides root nodules. Brazilian Journal of Microbiology, 42(2), 567-575. https://doi.org/10 $.1590 \% 2 F S 1517-838220110002000022$ 